\title{
Patient Safety Culture Change over Time-Health Care Staffs' Perceptions
}

\author{
Anna Nordin1, Gun Nordström 1,2, Bodil Wilde-Larsson1,2, Anders Hallberg3, \\ Kersti Theander ${ }^{1,4}$
}

${ }^{1}$ Faculty of Health, Science and Technology, Department of Health Science, Karlstad University, Karlstad, Sweden

${ }^{2}$ Faculty of Social and Health Sciences, Department of Health and Nursing Sciences, Inland Norway University of Applied Sciences, Elverum, Norway

${ }^{3}$ Department of Endocrinology and Diabetes, County Council of Värmland, Karlstad, Sweden

${ }^{4}$ Head of Centre for Clinical Research, County Council of Värmland, Karlstad, Sweden

Email: anna.nordin@kau.se

How to cite this paper: Nordin, A., Nordström, G., Wilde-Larsson, B., Hallberg, A. and Theander, K. (2020) Patient Safety Culture Change over Time-Health Care Staffs' Perceptions. Open Journal of Nursing, 10, 320-339.

https://doi.org/10.4236/ojn.2020.103022

Received: February 7, 2020

Accepted: March 28, 2020

Published: March 31, 2020

Copyright (c) 2020 by author(s) and Scientific Research Publishing Inc. This work is licensed under the Creative Commons Attribution International License (CC BY 4.0)

http://creativecommons.org/licenses/by/4.0/

(c) (i) Open Access

\begin{abstract}
Rationale and Aim: Patient safety is of great interest in health care organisations, worldwide. In Sweden, a national patient safety initiative was launched in 2011. The aim of this study was to examine and compare patient safety culture change over time from health care staffs' perspective. A further aim was to examine factors that have had an effect on patient safety culture. Methods: Patient safety culture was assessed in 2009, 2011 and 2013 using the Swedish version of the Hospital Survey of Patient Safety Culture. Respondents in this study were registered nurses $(\mathrm{n}=2149)$, enrolled nurses $(\mathrm{n}=$ 959), physicians $(\mathrm{n}=355)$ and managers $(\mathrm{n}=159)$ working in three health care divisions in a Swedish county council. Results: Patient safety culture decreased significantly over time for all but two dimensions. The dimension "Information to Patients/Relatives" was the only dimension to increase significantly over time. Health care staffs' profession and health care division belonging had significant main effects on 14 and 8 dimensions, respectively. Managers and enrolled nurses scored patient safety culture significantly higher than registered nurses and physicians. Health care staff working in a mixed medical-surgical health care division scored significantly higher than those working in medical or surgical divisions did. Conclusions: Despite efforts for patient safety work in the county council, health care staffs' perceptions of patient safety culture decreased over time. To improve hospital patient safety culture, managers and staff groups must meet and communicate with each other in order to create a common view of patient safety.
\end{abstract}




\section{Keywords}

Patient Safety Culture, Hospital, Three-Time Cross-Sectional, Healthcare

Organisations

\section{Introduction}

Since the early 1990s, international studies have shown that on average $3 \%-17 \%$ of all hospital patients will experience some form of harm as a result of their hospital stay [1]-[9]. The most recently completed measure in Sweden showed that $8 \%$ of all patients were affected by adverse events defined as suffering, physical or mental injury or illness, and death that could have been avoided if adequate measures had been taken by the health care services [10]. In response to figures like these, many countries have set up interventions to improve patient outcomes by means of reducing adverse events. Creating systems that support patient safety has been the primary goal of these interventions [11].

In 2011, the Swedish government and the Swedish Association of Local Authorities and Regions (SALAR) reached an agreement for improved patient safety. The agreement aimed to encourage, strengthen, and intensify patient safety work within all county councils in Sweden [12]. Important parts of the initiative included reducing adverse events, striving towards a culture of safety, preventive work, and comparisons of efforts and results. The Swedish government allocated 59 million euros to be distributed to those county councils fulfilling the basic demands of the agreement, e.g. establishing an annual patient safety report in accordance with the Patient Safety Act [13] and undertaking at least one patient safety culture measurement.

Swedish healthcare quality and safety is regulated in the overall Health Care Act [14] that outlines health care policies but does not specifically describe how to proceed with work focused on patient safety. The Patient Safety Act [13] describes health care staff's and employer's responsibilities for patient safety. Employers' obligations to conduct structured patient safety work is strongly emphasized and their responsibilities include, but are not limited to, negative event analysis, providing information to patients and relatives when adverse events occur, providing the opportunity for patients and relatives to involve in patient safety work, as well as writing annual reports regarding patient safety work at the workplace [13]. In the studied county council, the county council board decided that methods and tools for improved patient safety should be event analysis, risk analysis and journal reviews using Global Trigger Tool (GTT). Further, patient safety culture measurements using the Swedish version of the Hospital Survey on Patient Safety Culture (S-HSOPSC) and the structured framework tool for safe communication; Situation, Background, Assessment, and Recommendation (SBAR) were decided to be used. 
Patient safety culture, the specific aspect of the general culture in healthcare, refers to managerial and staff values, attitudes, and norms' concerning what is important for the safety of patients. Patient safety culture regulates behaviors and actions as well as systems for reward and punishment [15]. Management is a key element to create and encourage a strong patient safety culture. In such a culture, learning is highly valued among all staff and there is a quest to learn from mistakes and constantly improving performance. Managers and health care staff work in a spirit of collaboration, and relations are open, respectful, and flexible. Errors are recognized as system failures rather than individual failures, but at the same time individuals are held responsible for their actions. Further, in a health care setting with strong patient safety culture, structured communication is used to clarify verbal orders or to transfer information between healthcare staff or shifts. Health care staff communicates before and after procedures and managers provide feedback in order to acknowledge health care staff [16].

Earlier studies showed that aspects indicating patient safety culture strengths in hospitals were teamwork within [17] and across [18] health care units. Further, immediate [19] and remote [20] [21] managers promotion of safety as well as learning skills in an organization [22] were shown to indicate patient safety culture strengths. Patient safety culture also varies due to respondent's profession [23]. Here, physicians tend to score more positive opinions indicating patient safety culture strengths compared to nurses regarding reporting adverse events and managerial promotion of safety [23]. Furthermore, health care staff working in internal medicine and obstetric units scored more positively regarding communication openness in comparison to staff in other units, and this indicates that patient safety culture might vary depending on specialty [24]. Patient safety culture was also reported to vary due to sex [25] where women scored lower than men did. In several studies, patient safety culture also varied due to managerial function [26] [27] [28] [29], where managers scored more positive and favorable patient safety culture than non-managers did. Relations between a strong patient safety culture and positive patient outcomes were shown earlier [30] [31] [32] [33] [34]. Moreover, a positive correlation between patient safety culture, higher employee engagement and workplace safety was shown in a study using an abbreviated version of the Hospital Survey on Patient Safety Culture (HSOPSC) [35].

Modern health care is a complicated system and since many patients are negatively affected by adverse events, healthcare organizations are increasingly aware of the importance of patient safety. Many efforts to improve health care have focused on measuring system safety using reactive outcome measures [36] such as the assessment of adverse events. Over time, more attention has been directed towards the patient safety culture [37]. Health care staffs' patient safety culture is related to patient outcomes, and measurements of patient safety culture have come to form the basis of health care organizations' structured methods to gain an understanding of health care staffs' and managers' perceptions of safety. Re- 
peated patient safety culture measurements can be used to detect areas of weak patient safety or to track changes over time [38] [39] and to help health care managers and policymakers communicate what is important in an organization. Earlier studies of patient safety culture have almost entirely been cross-sectional or interventional and studies reporting patient safety culture measurements over time in parallel to patient safety work and the effect of factors on patient safety culture are scarce [35]. The assumption for the current study was an improvement in patient safety culture during the years in parallel to the efforts based on initiatives for better patient safety. Consequently, the aim of this study was to examine patient safety culture in a perspective over time.

\section{Aim}

The aim of this study was to examine and compare patient safety culture change over time from health care staffs' perspective. A further aim was to examine factors that have had an effect on patient safety culture.

\section{Methods}

\subsection{Design and Settings}

Location of this study was three health care divisions i.e. medical, surgical and mixed medical-surgical, out of nine in a county council in Sweden. The medical and the surgical health care divisions, including the senior management board, span over two separate hospitals. The mixed medical-surgical health care division constitutes of staff employed at a third hospital, led by a hospital manager and senior managers. Each health care division was led by a senior manager. The health care divisions were divided into a varying number of workplace units led by an operative manager.

\subsection{Sample and Procedure}

In October-November 2009, March 2011, and October-November 2013, the S-HSOPSC was disseminated as a web-based survey to included health care staff. In total, 6853 questionnaires were sent and 3721 valid questionnaires [40] were returned, yielding a response rate of $54 \%$. Information about the study was sent out via the staff newspaper and digitally on the staff intranet. Survey aim, information about voluntary participation and confidentiality was emphasized at information meetings and by e-mail to all managers at all levels and to the staff of the health care divisions. In 2009, the names and e-mail addresses of eligible respondents $(\mathrm{N}=2120)$ were obtained from nurse managers and personnel officers. In 2011 and 2013, names and e-mail addresses of eligible respondents ( $\mathrm{N}=$ 2172 and $N=2561$, respectively) were obtained from the county council's digital health care staff catalogue, to which all staff are connected. Data were collected by an external partner commissioned by the county council. The sample for this study consisted of registered nurses (RNs) $\mathrm{n}=2149$, enrolled nurses (ENs) $\mathrm{n}=$ 959 , physicians $n=355$, and managers $n=159$. Inclusion criteria were having 
direct contact with patients, working at least $50 \%$ time in the hospital, having been employed three months or more, and not being on extended sick or parental leave. The response rates for the sample are shown in Table 1.

\subsection{Patient Safety Activities in the Investigated County Council 2009-2013}

The national initiative for improved patient safety [12] influenced the county councils patient safety work conducted during the years of measurement. In 2009, a medical director service was established with the task to formulate the strategic and systematic patient safety work. A quality and safety unit (QSU) was established commissioned to systematically develop patient safety and effectiveness with a focus on measurements and education. All health care division managers collaborate with the internal development leaders of the health care divisions and the external leaders at the QSU. All managers are consistently educated in patient safety within the county council's continuous education for leaders. An upgraded common system for event reporting was reintroduced in the beginning of 2011 after being criticized as too time-consuming. Event analysis leaders were educated in order to intensify the systematic event analysis work. Patient safety culture measurements using the S-HSOPSC were conducted in 2009, 2011 and 2013, and the results were reported to the county council manager and the senior management boards. The operative managers, who inform the health care staff, were also given the results. The prevalence of health care-related infections, drug errors in the gap of health care, falls, and pressure ulcers were measured annually in 2009 and 2010. From 2011 onwards, these were measured on a monthly basis.

\subsection{The Questionnaire}

The US developed HSOPSC (44 items in 12 dimensions) was translated and adapted to Swedish health care context (S-HSOPSC) [41] by the National Board of Health and Welfare. In this version (51 items, 14 dimensions), the unit-level aspects of patient safety culture are measured with seven dimensions (24 items) and the hospital-level aspects are measured with three dimensions (11 items).

Table 1. Response rates distributed over time across health care divisions.

\begin{tabular}{ccccccc}
\hline & \multicolumn{2}{c}{2009} & \multicolumn{2}{c}{2011} & \multicolumn{2}{c}{2013} \\
\cline { 2 - 7 } & Sent & Returned & Sent & Returned & Sent & Returned \\
\cline { 2 - 6 } & $\mathrm{n}$ & $\mathrm{n}(\%)$ & $\mathrm{n}$ & $\mathrm{n}(\%)$ & $\mathrm{n}$ & $\mathrm{n}(\%)$ \\
\hline $\begin{array}{c}\text { Medical } \\
\text { Surgical }\end{array}$ & 999 & $439(44)$ & 1008 & $540(54)$ & 1139 & $658(58)$ \\
$\begin{array}{c}\text { Mixed } \\
\text { medical-surgical }\end{array}$ & 300 & $175(62)$ & 291 & $165(57)$ & 258 & $171(66)$ \\
Total & 2120 & $1023(48)$ & 2172 & $1228(57)$ & 2561 & $1470(57)$ \\
\hline
\end{tabular}


The single item Number of Events reported over 12 months serves as a descriptive measure. Two dimensions and one single-item ( 8 items) serve as outcome measures. Two dimensions (six items) and one single-item were added reflecting patient safety culture within a Swedish health care context. Most items are answered using a five-point response scale of agreement ( 1 = "Strongly Disagree" to $5=$ "Strongly Agree"), frequency ( $1=$ "Never" to $5=$ "Always"), or quality ( $1=$ "Failing" to 5 = "Excellent") where a higher score indicates strengths in patient safety. Two items use a six-point frequency scale from "No Event" to "21 Events or more" or "No Risk" to "21 risks or more".

The S-HSOPSC has been psychometrically investigated and tested and found to be acceptable for measuring patient safety culture in large and small hospital settings [42] [43]. Internal consistency measured by means of Cronbach's alpha for the 14 dimensions of the S-HSOPSC varied between 0.58 and 0.87 . The dimensions "Organizational Learning", "Teamwork within Hospital Units", "Staffing”, and "Communication Openness" showed a Cronbachs' alpha $<0.7$ for the survey conducted in 2009 and 2011. For the survey conducted in 2013, the same dimensions except for "Teamwork Within Hospital Units" ( $\alpha=0.73)$ again showed a Cronbachs' alpha values $<0.7$. Remaining dimensions exhibited Cronbachs' alpha values > 0.7 in the surveys conducted in 2009, 2011 and 2013.

In addition to the patient safety culture dimensions, a demographic section asks questions about sex, age, staff group, total experience within health care and in the hospital work unit. In this section, the respondents also have the opportunity to tick if they have direct contact with patients and to provide the length of time they have worked in their current specialty or profession. The S-HSOPSC questionnaire used in this study can be read elsewhere [43].

\subsection{Statistical Analyses}

The data were summarized as frequencies and percentages (nominal and ordinal data), mean and standard deviation (interval data). A four-way analysis of variance (ANOVA) was performed to examine a systematic change [44] in patient safety culture due to the categorical factors staff group (RN, EN, physician, manager), the health care division to which one belongs (medical, surgical, mixed medical-surgical), the year of measurement (2009, 2011, 2013), and sex (female/male). The interactions between these factors were also assessed. Because studies have shown patient safety culture to vary in relation to sex, this variable was kept only as a control variable. Significant F-levels in the ANOVA were followed by Tukey's test for post-hoc comparisons to analyze differences in the means for the respective dimensions of the S-HSOPSC in 2009, 2011, and 2013 (grand mean) [44]. To avoid the risk of type I errors due to mass-significance, significance level was set at $p \leq 0.01$. Statistical analyses were conducted using IBM Statistical Package for Social Sciences (SPSS) version 20.0.

\subsection{Ethical Considerations}

Before the study was carried out, the project underwent ethical review and ap- 
proval by the local ethics committee (Dnr. C 2009/304). In addition, the County Council Manager and each health care division's senior management board gave approval of the study. Data were handled according to the Personal Data Act (1988) supervised by the Data Inspection Board. Respondents received verbal and written information prior to participation which was voluntary and confidential [45].

\section{Results}

Health care staff working in the mixed medical-surgical health care division displayed a higher \%-response rate than both the other two divisions in 2009 and 2013 and a response rate above the total on two occasions. Most respondents were women and between 45 to 54 years old. The majority had a total work experience of $>16$ years. On all three occasions for data collection, nurses were the largest group of the respondents. Table 2 shows the characteristics of the respondents for the measurement occasions in 2009, 2011, and 2013.

Table 2. Respondent characteristics.

\begin{tabular}{|c|c|c|c|}
\hline & 2009 & 2011 & 2013 \\
\hline \multirow[t]{2}{*}{ Total (N) } & 1023 & 1228 & 1470 \\
\hline & $\mathrm{n}(\%)$ & $\mathrm{n}(\%)$ & $\mathrm{n}(\%)$ \\
\hline \multicolumn{4}{|l|}{ Sex } \\
\hline Female & $871(85)$ & $1027(84)$ & $1132(77)$ \\
\hline Male & $152(15)$ & $176(14)$ & $253(17)$ \\
\hline Unknown & 0 & $25(2)$ & $85(6)$ \\
\hline \multicolumn{4}{|l|}{ Age } \\
\hline-24 & $17(2)$ & $24(2)$ & $31(2)$ \\
\hline $25-34$ & $126(12)$ & $195(16)$ & $268(18)$ \\
\hline $35-44$ & $247(24)$ & $295(24)$ & 285 (19) \\
\hline $45-54$ & $357(35)$ & $395(32)$ & $425(29)$ \\
\hline $55-64$ & $210(20)$ & $275(22)$ & $384(26)$ \\
\hline $65-$ & $7(1)$ & $3(1)$ & $7(1)$ \\
\hline Unknown & $56(6)$ & $38(3)$ & $70(5)$ \\
\hline \multicolumn{4}{|c|}{ Total work experience (years) } \\
\hline $0-5$ & $83(8)$ & $153(12)$ & $206(14)$ \\
\hline $6-10$ & $114(11)$ & $159(13)$ & $174(12)$ \\
\hline $11-15$ & $90(9)$ & $137(11)$ & $186(13)$ \\
\hline $16-20$ & $90(9)$ & $121(10)$ & $121(8)$ \\
\hline $21-50$ & $579(56)$ & $636(52)$ & $706(48)$ \\
\hline Unknown & $67(7)$ & $22(2)$ & $77(5)$ \\
\hline \multicolumn{4}{|l|}{ Staff group } \\
\hline Managers & $51(5)$ & $44(4)$ & $64(4)$ \\
\hline Registered Nurse $\mathrm{e}^{1}$ & $617(64)$ & $743(61)$ & $789(54)$ \\
\hline Enrolled Nurse ${ }^{1}$ & $293(29)$ & $302(25)$ & $364(25)$ \\
\hline Physician $^{1}$ & $62(7)$ & $119(10)$ & $174(12)$ \\
\hline Unknown & 0 & $20(2)$ & $81(6)$ \\
\hline${ }^{1}$ Non manager & & & \\
\hline
\end{tabular}




\subsection{Changes in Patient Safety Culture over Time}

Patient safety culture decreased significantly over time for 12 out of the $14 \mathrm{di}$ mensions. Patient safety culture increased significantly over time for the dimension "Information to Patients/Relatives" and did not change over time for the dimension "Information to Staff" (Figure 1).

\subsection{Effects on Patient Safety Culture}

The 14 patient safety culture dimensions and the factors having a main effect or interaction effect on them are depicted in Table 3.

The respondent's profession had a significant main effect on all 14 dimensions, including outcome measures and the unit-level, hospital-level, and Swedish added dimensions. For six dimensions, there was an interaction effect of profession together with the other factors on the patient safety culture. The health care division to which one belongs had a significant main effect on eight out of 14 dimensions, including the Outcome Measure dimension "Overall Perceptions of Safety" $(p=0.002)$ and the Unit level dimensions "Organizational Learning" ( $p=0.003)$, “Teamwork Within Hospital Units" $(p=0.002)$, and "Staffing" ( $p=0.002)$. The health care division also had a significant main effect on all dimensions at the hospital level $(\mathrm{p} \leq 0.001)$ and the Swedish-specific dimension "Information to Patient/Relatives" $(\mathrm{p}=0.007)$. For eight dimensions

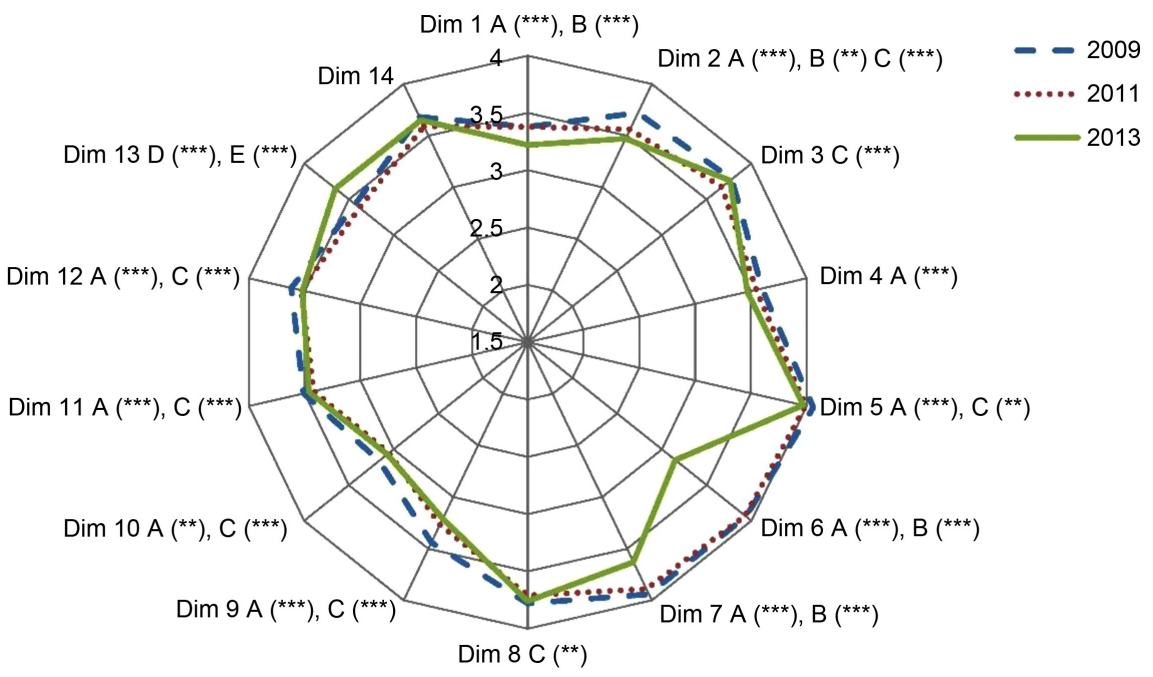

Figure 1. Health care staffs' perceptions of patience safety culture over time (2009 $\mathrm{n}=$ $1023,2011 \mathrm{n}=1228,2013 \mathrm{n}=1470$ ). Decreasing scores approach the center of the figure and inversely for increasing scores. $A=2009>2013, \mathrm{~B}=2011>2013, \mathrm{C}=2009>2011$, $\mathrm{D}=2013>2009, \mathrm{E}=2013>2011 .{ }^{* *}=\mathrm{p}<0.01,{ }^{* *}=\mathrm{p}<0.001$. Dimension 1: Frequency of event reporting; Dimension 2: Overall perception of safety; Dimension 3: Manager promoting safety; Dimension 4: Organizational learning; Dimension 5: Teamwork within hospital units; Dimension 6: Communication openness; Dimension 7: Feedback and communication; Dimension 8: Nonpunitive response to error; Dimension 9: Staffing; Dimension 10: Hospital management support; Dimension 11: Teamwork across hospital units; Dimension 12: Hospital handoffs and transitions; Dimension 13: Information to patience/relatives; Dimension 14: Information to staff. 
Table 3. Factors having effect on patient safety culture.

\begin{tabular}{|c|c|c|c|c|c|c|}
\hline $\begin{array}{l}\text { S-HSOPSC } \\
\text { dimension }\end{array}$ & $\begin{array}{l}\text { Main effect } \\
\text { of staff } \\
\text { group }\end{array}$ & $\begin{array}{c}\text { Main effect } \\
\text { of Health } \\
\text { Care Division }\end{array}$ & $\begin{array}{l}\text { Main effect } \\
\text { of Year }\end{array}$ & $\begin{array}{l}\text { Interaction with } \\
\text { staff group }\end{array}$ & $\begin{array}{l}\text { Interaction with } \\
\text { Health Care } \\
\text { Division }\end{array}$ & $\begin{array}{l}\text { Interaction } \\
\text { with Year }\end{array}$ \\
\hline \multicolumn{7}{|l|}{ Outcome Measures } \\
\hline $\begin{array}{l}\text { Frequency of Event } \\
\text { Reporting }\end{array}$ & $\mathrm{X}$ & & $\mathrm{X}$ & & $\mathrm{X}$ & \\
\hline $\begin{array}{l}\text { Overall Perceptions } \\
\text { of Safety }\end{array}$ & $\mathrm{X}$ & $\mathrm{X}$ & $\mathrm{x}$ & & $\mathrm{X}$ & \\
\hline \multicolumn{7}{|l|}{ Unit Level } \\
\hline Manager Promoting safety & $\mathrm{X}$ & & & & $\mathrm{X}$ & $\mathrm{x}$ \\
\hline Organizational Learning & $\mathrm{X}$ & $\mathrm{X}$ & & $\mathrm{X}$ & & \\
\hline $\begin{array}{l}\text { Teamwork Within } \\
\text { Hospital Units }\end{array}$ & $\mathrm{X}$ & $\mathrm{X}$ & $\mathrm{X}$ & $\mathrm{X}$ & $\mathrm{X}$ & \\
\hline Communication Openness & $\mathrm{X}$ & & $\mathrm{X}$ & & & \\
\hline Feedback and Communication & $\mathrm{X}$ & & & $\mathrm{X}$ & & \\
\hline $\begin{array}{l}\text { Nonpunitive Response } \\
\text { To Error }\end{array}$ & $\mathrm{X}$ & & & & & \\
\hline Staffing & $\mathrm{X}$ & $\mathrm{X}$ & $\mathrm{X}$ & $\mathrm{X}$ & $\mathrm{X}$ & \\
\hline \multicolumn{7}{|l|}{ Hospital Level } \\
\hline $\begin{array}{l}\text { Hospital Management } \\
\text { Support }\end{array}$ & $\mathrm{X}$ & $\mathrm{X}$ & & & $\mathrm{X}$ & $\mathrm{X}$ \\
\hline Teamwork Across Hospital Units & $\mathrm{X}$ & $\mathrm{X}$ & $\mathrm{X}$ & $\mathrm{X}$ & $\mathrm{X}$ & \\
\hline Hospital Handoffs and Transitions & $\mathrm{X}$ & $\mathrm{X}$ & $\mathrm{X}$ & $\mathrm{X}$ & & \\
\hline \multicolumn{7}{|l|}{ Swedish Added } \\
\hline $\begin{array}{l}\text { Information to } \\
\text { Patient/Relatives }\end{array}$ & $\mathrm{X}$ & $\mathrm{X}$ & $\mathrm{X}$ & & $\mathrm{X}$ & \\
\hline Information to Staff & $\mathrm{X}$ & & & & & \\
\hline
\end{tabular}

there was an interaction effect of the health care division to which one belongs on the patient safety culture. The year of the survey had a significant main effect on eight out of the 14 dimensions, and for two dimensions there was an interaction effect on the patient safety culture.

\subsection{Comparisons between Groups}

\subsubsection{Staff Groups}

Table 4 shows the different staff groups' grand mean scores of patient safety culture. Managers scored higher for all 14 dimensions compared to non-managers. ENs scored higher than RNs and physicians for 10 and 13 dimensions, respectively, and these differences were distributed among outcome measures and the unit-level, hospital-level, and Swedish added dimensions. RNs scored higher than physicians and ENs for seven and for one dimension, respectively, and the differences were distributed among outcome measures and the unit-level and hospital-level dimensions. Physicians scored higher than RNs for the Swedish 
Table 4. Staff group grand mean scores of patient safety culture.

\begin{tabular}{|c|c|c|c|c|c|}
\hline \multirow[t]{2}{*}{$\begin{array}{l}\text { S-HSOPSC } \\
\text { dimension }\end{array}$} & $\begin{array}{l}\text { Registered } \\
\text { Nurses (1) } \\
(n=2113)\end{array}$ & $\begin{array}{c}\text { Enrolled } \\
\text { Nurses (2) } \\
(n=941)\end{array}$ & $\begin{array}{c}\text { Physicians } \\
\text { (3) } \\
(n=342)\end{array}$ & $\begin{array}{c}\text { Managers } \\
(4) \\
(n=159)\end{array}$ & \multirow[t]{2}{*}{$p$} \\
\hline & Mean (SD) & Mean (SD) & Mean (SD) & Mean (SD) & \\
\hline \multicolumn{6}{|l|}{ Outcome Measures } \\
\hline Frequency of Event Reporting ${ }^{1}$ & $3.26(0.04)$ & $3.53(0.04)$ & $2.91(0.06)$ & $3.55(0.07)$ & $1>3 ; 2>1,3 ; 4>1,3^{\star * *}$ \\
\hline Overall Perceptions of Safety ${ }^{2}$ & $3.62(0.03)$ & $3.77(0.04)$ & $3.31(0.05)$ & $3.92(0.07)$ & $1>3 ; 2>1,3 ; 4>1,3^{* * *}$ \\
\hline \multicolumn{6}{|l|}{ Unit Level } \\
\hline Manager Promoting safety ${ }^{2}$ & $3.67(0.02)$ & $3.88(0.03)$ & $3.59(0.05)$ & $4.0(0.07)$ & $2>1,3 ; 4>1,3^{* * *}$ \\
\hline Organizational Learning ${ }^{2}$ & $3.47(0.02)$ & $3.59(0.05)$ & $3.41(0.04)$ & $3.82(0.07)$ & $2>1,3 ; 4>1,2,3^{\star * *}$ \\
\hline Teamwork Within Hospital Units ${ }^{2}$ & $4.00(0.02)$ & $4.02(0.04)$ & $3.93(0.05)$ & $4.2(0.06)$ & $1>3 ; 2>3 ; 4>1,2,3^{* * *}$ \\
\hline Communication Openness $^{1}$ & $3.67(0.02)$ & $3.7(0.02)$ & $3.65(0.04)$ & $4.00(0.05)$ & $1>3 ; 2>3^{* *} ; 4>1,2,3^{* * *}$ \\
\hline Feedback and Communication ${ }^{1}$ & $3.70(0.04)$ & $3.83(0.07)$ & $3.44(0.07)$ & $4.00(0.08)$ & $1>3 ; 2>3 ; 4>1,3^{* * *}$ \\
\hline Nonpunitive Response to Error ${ }^{2}$ & $3.69(0.03)$ & $3.74(0.06)$ & $3.53(0.05)$ & $4.28(0.08)$ & $2>1,3,4 ; 4>1,2,3^{\star * *}$ \\
\hline Staffing $^{2}$ & $3.43(0.02)$ & $3.29(0.02)$ & $2.96(0.06)$ & $3.66(0.06)$ & $1>2,3 ; 2>3 ; 4>1,2,3^{* * x}$ \\
\hline \multicolumn{6}{|l|}{ Hospital Level } \\
\hline Hospital Management Support ${ }^{2}$ & $2.98(.02)$ & $3.28(0.03)$ & $3.1(0.07)$ & $3.59(0.07)$ & $2>1,3 ; 4>1,2,3^{* * *}$ \\
\hline Teamwork Across Hospital Units ${ }^{2}$ & $3.39(.04)$ & $3.52(0.04)$ & $3.51(0.05)$ & $3.70(0.06)$ & $2>1,3 ; 4>1,3^{* * *}$ \\
\hline Hospital Handoffs and Transitions ${ }^{2}$ & $3.55(.03)$ & $3.66(0.05)$ & $3.17(0.05)$ & $3.56(0.07)$ & $1>3 ; 2>1,3 ; 4>3^{* * *}$ \\
\hline \multicolumn{6}{|l|}{ Swedish Added Dimensions } \\
\hline Information to Patient/Relatives ${ }^{2}$ & $3.32(.03)$ & $3.7(0.04)$ & $3.67(0.05)$ & $3.81(0.07)$ & $2>1 ; 3>1 ; 4>1^{* * *}$ \\
\hline Information to Staff ${ }^{2}$ & $3.52(.02)$ & $3.84(0.03)$ & $3.52(0.08)$ & $4.12(0.08)$ & $2>1,3 ; 4>1,2,3^{* * *}$ \\
\hline
\end{tabular}

${ }^{1}$ Response alternative ranging from 1 (Never) to 5 (Always). ${ }^{2}$ Response alternative ranging from 1 (Strongly Disagree) to 5 (Strongly Agree). ${ }^{* *}=\mathrm{p}<0.01$, ${ }^{* * *}=\mathrm{p}<0.001$.

added dimension "Information to Patients/Relatives".

\subsubsection{Health Care Division}

Health care staff working in the mixed medical-surgical health care division scored higher grand mean than those working in the surgical and medical health care divisions for eight dimensions, respectively. Differences were distributed among outcome measures and the unit-level, hospital-level, and the Swedish added dimensions. Health care staff working in the medical health care division scored higher than those working in the surgical health care division scored for three dimensions did. Differences were distributed among outcome measures and unit-level and hospital-level dimensions (Table 5).

\section{Discussion}

The foremost result of this study shows that health care staffs' perception of patient safety culture significantly decreased over time for all dimensions except two. The only dimension to increase over time was the dimension regarding information to patients or relatives in connection with mistakes. We also showed 
Table 5. Health care division grand mean scores of patient safety culture.

\begin{tabular}{|c|c|c|c|c|}
\hline \multirow{2}{*}{$\begin{array}{l}\text { S-HSOPSC } \\
\text { dimension }\end{array}$} & $\begin{array}{c}\text { Medical (1) } \\
(n=1637)\end{array}$ & $\begin{array}{l}\text { Surgical (2) } \\
(n=1573)\end{array}$ & $\begin{array}{c}\text { Mixed (3) } \\
(n=511)\end{array}$ & \multirow[t]{2}{*}{$p$} \\
\hline & Mean (SD) & Mean (SD) & Mean (SD) & \\
\hline \multicolumn{5}{|l|}{ Outcome Measures } \\
\hline Frequency of Event Reporting ${ }^{1}$ & $3.28(0.03)$ & $3.29(0.03)$ & $3.36(0.08)$ & $3>2^{* * *}$ \\
\hline Overall Perceptions of Safety ${ }^{2}$ & $3.55(0.03)$ & $3.66(0.03)$ & $3.76(0.08)$ & $3>1^{* *} ; 3>2^{* * *}$ \\
\hline \multicolumn{5}{|l|}{ Unit Level } \\
\hline Manager Promoting safety ${ }^{2}$ & $3.78(0.03)$ & $3.77(0.03)$ & $3.80(0.04)$ & NS \\
\hline Organizational Learning $^{2}$ & $3.60(0.03)$ & $3.52(0.03)$ & $3.59(0.04)$ & $1>2^{\star \star}$ \\
\hline Teamwork Within Hospital Units ${ }^{2}$ & $4.05(0.03)$ & $3.96(0.03)$ & $4.10(0.05)$ & NS \\
\hline Communication Openness ${ }^{1}$ & $3.74(0.02)$ & $3.76(0.02)$ & $3.77(0.03)$ & $3>1^{\star *}$ \\
\hline Feedback and Communication ${ }^{1}$ & $3.75(0.03)$ & $3.73(0.04)$ & $3.95(0.08)$ & $1>2 ; 3>1,2^{* * *}$ \\
\hline Nonpunitive Response to Error ${ }^{2}$ & $3.82(0.03)$ & $3.82(0.03)$ & $3.78(0.05)$ & NS \\
\hline Staffing ${ }^{2}$ & $3.25(0.03)$ & $3.32(0.03)$ & $3.46(0.05)$ & $3>1 ; 3>2 * *$ \\
\hline \multicolumn{5}{|l|}{ Hospital Level } \\
\hline Hospital Management Support ${ }^{2}$ & $3.02(0.03)$ & $3.02(0.03)$ & $3.65(0.06)$ & $3>1,2^{* * *}$ \\
\hline Teamwork Across Hospital Units ${ }^{2}$ & $3.39(0.03)$ & $3.37(0.03)$ & $3.83(0.06)$ & $3>1,2^{\star * *}$ \\
\hline Hospital Handoffs and Transitions ${ }^{2}$ & $3.42(0.03)$ & $3.34(0.03)$ & $3.69(0.05)$ & $1>2 ; 3>1,2^{* * *}$ \\
\hline \multicolumn{5}{|l|}{ Swedish Added Dimensions } \\
\hline Information to Patient/Relatives ${ }^{2}$ & $3.52(0.03)$ & $3.60(0.03)$ & $3.75(0.08)$ & $3>1,2^{* * *}$ \\
\hline Information to Staff $^{2}$ & $3.70(0.04)$ & $3.67(0.04)$ & $3.89(0.07)$ & $3>1^{* *} ; 3>2^{* * *}$ \\
\hline
\end{tabular}

${ }^{1}$ Response alternative ranging from 1 (Never) to 5 (Always). ${ }^{2}$ Response alternative ranging from 1 (Strongly Disagree) to 5 (Strongly Agree). ${ }^{\star *}=\mathrm{p}<0.01$, $* * *=\mathrm{p}<0.001$.

that the perception of patient safety culture differed in relation to managerial function and the health care division to which one belongs.

In the light of the postulated goals for improved patient safety in Swedish hospitals [12], these results show difficulties in the efficacy of implementing national actions for patient safety [12] [13] in the county council of the present study. Complex social interventions, such as these are likely to result in limited improvement and disappointment when there is little understanding of how the intervention programs work [46]. To change a complex system such as a health care organization and the patient safety culture within that system takes time [47]. This might be reflected by the fact that health care staff's attitude towards safety did not increase despite the efforts taken from 2009 to 2013. Thus changes might not become apparent until further into the future when patient safety culture has been measured for a longer period of time.

The dimension "Communication Openness", which is strongly connected to health care staffs' ability to raise concerns about patient safety issues without being afraid of retaliation, showed the largest decline. This result is very troublesome because it is well known that a strong patient safety culture is characterized by trustful communication and a blame-free atmosphere when errors are 
reported [48] [49]. The dimensions "Organizational Learning", "Staffing", and "Hospital Management Support" also showed large declines that altogether might reflect "organizational fatigue" [50] and avoidant leadership [51] in situations where employees have resigned. The decline in "Staffing" reflects health care staffs' workload and staff ratios and raises concerns about patient safety deficiencies and mortality as a result of staff shortages as recently presented [52].

In the present study, the only dimension to increase over time was "Information to Patients/Relatives" that concerns the information and details given to patients and/or relatives in connection to a negative event. This finding might be related to the overriding and distinct wording in the Patient Safety Act - under which all health care staff operate - stating that the provider of health care "shall quickly inform a patient affected by negative events", $8 \$, 3^{\text {rd }}$ chapter [13]. Yet another law, the Patients' Act [53], which had been proposed in order to strengthen the patients' position, might have heightened health care staffs' view of the patient as the central decision-maker regarding their own care.

In the present study, managers scored patient safety culture higher than non-managers for all 14 dimensions. Since managers continue to report higher levels of patient safety culture i.e. better patient safety culture compared to health care staff working in direct contact with patients [27], it is important for managers to act upon this. This gap in perception of patient safety culture needs to be bridged; all health care staff must agree about the situation in order to carry out practical changes to improve patient safety. Evidence regarding efficacy of interventions aiming to promote safety culture is emerging [54], and it is becoming clear that the manager's role in achieving patient safety is essential [55] [56]. Thus, it is troubling that managers, who play a prominent role in patient safety improvement, do not share the same perception of the state of patient safety as the other staff groups within the health care.

Physicians scored lower than RNs for the dimension "Communication Openness", which deals with aspects of communicating when health care staff sees something that might negatively affect the patients and to intervene when persons in higher hierarchical positions make decisions or perform in a manner that might negatively affect the patients. This result is in line with another study where physicians were less likely than RNs to approve of patient involvement and to intervene in preventing potential errors that threaten patient safety [57]. This perception might indicate that this profession has a greater degree of introversion within the group. Such a trait is not typically supportive of improving patient safety culture and might, therefore, be a good target for interventions such as patient safety dialogues or discussions aiming to engender an open and honest culture where discussions regarding being reviewed are normalized and seen as common practice.

ENs scored higher than RNs and physicians for multiple dimensions. This result is supported by earlier studies of patient safety culture nursing homes [58] and might reflect that RNs and physicians are more educated in critical thinking. 
In a study focusing on developing ENs' engagement in patient safety, staff education led to lower fall rates among patients [59] indicating that ENs have an important role to play in patient safety improvement. A lack of awareness of overall quality and safety issues due to working closely with patients over time [60] might explain the differences in perceptions between the different professions. To overcome these differences, health care organizations could implement patient safety rounds or dialogues where health care staff from different staff groups meet and discuss issues of importance for patient safety in their specific unit [61] [62]. Interprofessional discussions and communication are important for efficient workflows and for developing professions [63] [64], and interprofessional teamwork has been shown to improve patient safety and workplace culture [65].

In this study, health care staff affiliated with the medical health care divisions scored higher than those working in surgical health care division did for several dimensions. This is contradictory to the findings of Tvedt et al. (2012) where RNs affiliated with medical wards scored lower for patient safety culture than RNs working in surgical departments [66]. However, another study reported that health care staff working in internal medicine scored higher in comparison to staff in other units regarding the patient safety culture dimension "Communication Openness" [24]. These contradictory results indicate that workplace leadership might be of greater importance in supporting patient safety culture than the type of care on the workplace.

\section{Methodological Considerations}

This examination of health care staffs' perception of patient safety culture was conducted using three measurements in the same health care divisions over a five-year period. This is a strength and adds great weight to the results. It is also a strength that the measurements were conducted both in medical and surgical surroundings where adverse events are prone to occur [5]. This makes the results important to be taken seriously. The use of the Swedish Hospital Survey on Patient Safety Culture, a psychometrically tested questionnaire [42] [43], as well as ensuring accuracy when performing the tests and using caution when interpreting the results, e.g., avoiding the risk of conducting type I errors [67], also provide internal validity to this study.

Internal consistency as measured by Cronbach's alpha for the 14 dimensions varied between 0.58 and 0.87 for the measurement in 2009, where "Staffing" showed the lowest values and "Frequency of Event Reporting" showed the highest values. For the measurement conducted in 2011, "Staffing" showed a value of 0.65 and "Frequency of Event Reporting" 0.84. In 2013, "Communication Openness" showed a value of 0.64 and "Information to Patients/Relatives" 0.87. The dimensions showing Cronbach's alpha values $<0.70$ in this study exhibited the same levels consistently, and the results must be interpreted accordingly. The questions in these dimensions might benefit from a review in order to streng- 
then the internal consistency [67].

In the present study, all RNs, ENs, physicians and managers at the three health care divisions were invited to participate. These health care professions interact directly with patients in hospitals and their actions might affect patient safety on an everyday basis. The inclusion of these different health care professions gives a variation of perspectives and makes the results possible to generalize to health care organizations with similar staffing arrangements. Furthermore, the distribution of professions in the present study rather well corresponds with the eligible sample and the national distribution [68] which strengthens the study.

In total, 6856 questionnaires were sent over the study period and 3721 were returned making up a response rate of $54 \%$. This might be considered somewhat low, but given that the study was conducted as a web survey, it can be seen as average [69]. Over the measurement period, the response rate increased, and this might be due to health care staffs' increased awareness of the importance the county council placed on participating in patient safety work. The response rate during the study period remained stable for the ENs but the response rate for RNs decreased. In the present study, the response rate for physicians increased over time, and this might be due to the survey mode; web-based surveys are increasingly being used by physicians and reminders by e-mail increase their response rate [70].

This study was conducted as a survey of patient safety culture measured over a period of four years. Some respondents might be found in all data collections while some might be present for only one or two measurement occasions. Although the definition of a longitudinal survey calls for having the same participants in all data collections by some [71], others argue for a study with data collected at more than one point of time over an extended period to be longitudinal [72]. Having the same participants in all data collections was not possible to implement in the present study, and to make the samples as similar as possible the same health care staff professionals and the same health care divisions in the same hospitals were chosen. Patient safety culture is known to change slowly over long periods of time [47], and this approach makes it possible to examine patient safety culture over time.

Patient safety culture reflects health care staffs' attitudes, beliefs and approach to safety for patients within an organization. It must be noted, though, that reporting health care staffs' perceptions of patient safety culture does not necessarily imply an operationalization of this. However, a comprehensive picture is beginning to emerge in the field of patient safety culture suggesting that a strong patient safety culture is directly associated with positive patient safety outcomes [54]. This study was performed over a five-year period. Although the data was collected some years ago, no other studies have been identified where HSOPSC was used to examine hospital patient safety culture for an extended period where data was collected on more than two occasions. This emphasizes the significance 
and innovation of this study.

\section{Conclusion}

Patient safety culture decreased over the examined time despite considerable efforts for patient safety. The factor staff group showed a main effect on all patient safety culture dimensions, and managers scored higher for all dimensions in comparison to RNs, ENs, and physicians. In order to improve hospital patient safety culture, staff groups need to meet and communicate with each other. In order to create a shared, common view of patient safety culture within a large organization such as a division or a hospital made up of several smaller units, staff groups from different units must discuss these matters in open, non-judgmental groups where all participants have equal power and responsibility to improve patient safety.

\section{Further Research}

In the future, it is also necessary to conduct intervention studies in the field of patient safety culture to examine the effect of the implemented efforts in health care. Interviews with health care staff or qualitative analysis of the questionnaire's open comment section would complement the quantitative perspective of patient safety culture and give a voice to health care staffs' narratives of safety work on an everyday basis. Studying health care staffs' patient safety culture related to the patients' experience of quality in health care in areas frequently affected by adverse events would further broaden our knowledge of patient safety culture.

\section{Conflicts of Interest}

The authors declare no conflicts of interest regarding the publication of this paper.

\section{References}

[1] Brennan, T., Leape, L., Laird, N., Hebert, L., Localio, R., Lawthers, A., et al. (1991) Incidence of Adverse Events and Negligence in Hospitalized Patients. Results of the Harvard Medical Practice Study I. The New England Journal of Medicine, 324, 370-376. https://doi.org/10.1056/NEJM199102073240604

[2] Wilson, R.M., Runciman, W.B., Gibberd, R.W., Harrison, B.T., Newby, L. and Hamilton, J.D. (1995) The Quality in Australian Health Care Study. The Medical Journal of Australia, 163, 458-471. https://doi.org/10.5694/j.1326-5377.1995.tb124691.x

[3] Thomas, E., Studdert, D., Burstin, H., Orav, J., Zeena, T., Williams, E., et al. (2000) Incidence and Types of Adverse Events and Negligent Care in Utah and Colorado. Medical Care, 38, 261- 271. https://doi.org/10.1097/00005650-200003000-00003

[4] Schiøler, T., Lipczak, H., Pedersen, B.L., Mogensen, T.S., Bech, K.B., Stockmarr, A., et al. (2001) Forekomsten af utilsigtede hændelser på sygehuse. Enretrospektivgennemgangafjournaler. UgeskrLaeger, 163, 5370.

[5] Vincent, C., Neale, G. and Woloshynowych, M. (2001) Adverse Events in British 
Hospitals: Preliminary Retrospective Record Review. British Medical Journal, 322, 517-519. https://doi.org/10.1136/bmj.322.7285.517

[6] Davis, P., Lay-Yee, R., Briant, R., Ali, W., Scott, A. and Schug, S. (2002) Adverse Events in New Zealand Public Hospitals I: Occurrence and Impact. New Zealand Medical Journal, 115, 271-279.

[7] Baker, R., Norton, P., Flintoft, V., et al. (2004) The Canadian Adverse Events Study: The Incidence Of Adverse Events among Hospital Patients in Canada. Canadian Medical Association Journal, 170, 1678-1686. https://doi.org/10.1503/cmaj.1040498

[8] Soop, M., Fryksmark, U., Köster, M. and Haglund, B. (2009) The Incidence of Adverse Events in Swedish Hospitals: A Retrospective Medical Record Review Study. International Journal for Quality in Health Care, 21, 285-291. https://doi.org/10.1093/intqhc/mzp025

[9] Zegers, M., de Bruijne, M.C., Wagner, C., et al. (2009) Adverse Events and Potentially Preventable Deaths in Dutch Hospitals: Results of a Retrospective Patient Record Review Study. Quality and Safety in Health Care, 18, 297-302. https://doi.org/10.1136/qshc.2007.025924

[10] Skador i vården-utveckling (2013-2017) Markörbaserad journalgranskning. SKR. Adverse Events in Health Care-Development 2013-2017. Cursor Based Review of Medical Records. SALAR. (In Swedish)

[11] Kohn, L., Corrigan, J. and Donaldson, M. (2000) To Err Is Human: Building a Safer Health System. National Academies Press, Washington DC.

[12] Patientsäkerhetssatsning (2012) Överenskommelse mellan staten och Sveriges Kommuner och Landsting om förbättrad patientsäkerhet. [Patient Safety Initiative 2012. Agreement between the Swedish Government and the Swedish Association of Local Authorities (SALAR)]. (In Swedish)

[13] SFS 2010:659. Patient Safety Act (2010) Government Offices of Sweden. Ministry of Health and Social Affairs, Stockholm. [Patientsäkerhetslagen (2010) Sveriges Riksdag. Socialdepartementet, Stockholm]. (In Swedish)

[14] SFS 1982:763 Health Care Act (1982) Government Offices of Sweden. Ministry of Health and Social Affairs, Stockholm. [Hälso- och sjukvårdslagen (1982) Sveriges Riksdag. Socialdepartementet, Stockholm]. (In Swedish)

[15] Sorra, J and Dyer, N. (2010) Multilevel Psychometric Properties of the AHRQ Hospital Survey on Patient Safety Culture. Health Services Research, 10, 199. https://doi.org/10.1186/1472-6963-10-199

[16] Sammers, C., Lykens, K., Singh, K., Mains, D. and Lackan, N. (2010) What Is Patient Safety Culture? A Review of the Literature. Journal of Nursing Scholarship, 42, 156-165. https://doi.org/10.1111/j.1547-5069.2009.01330.x

[17] Snijders, C., Kollen, B., van Lingen, R., Fetter, W. and Molendijk, H. (2009) Which Aspects of Safety Culture Predict Incident Reporting Behavior in Neonatal Intensive Care Units? A Multilevel Analysis. Critical Care Medicine, 37, 61-67. https://doi.org/10.1097/CCM.0b013e31819300e4

[18] Chen, C. and Li, H. (2010) Measuring Patient Safety Culture in Taiwan Using the Hospital Survey on Patient Safety Culture (HSOPSC). Health Services Research, 10, 152. https://doi.org/10.1186/1472-6963-10-152

[19] Ballangrud, R., Hedelin, B. and Hall-Lord, M.L. (2012) Nurses' Perceptions of Patient Safety Climate in Intensive Care Units: A Cross-Sectional Study. Intensive and Critical Care Nursing, 28, 344-54. https://doi.org/10.1016/j.iccn.2012.01.001

[20] Wagner, L.M., Capezuti, E. and Rice, J.C. (2009) Nurses' Perceptions of Safety Cul- 
ture in Long-Term Care Settings. Journal of Nursing Scholarship, 41, 184-192. https://doi.org/10.1111/j.1547-5069.2009.01270.x

[21] Alahmadi, H.A. (2010) Assessment of Patient Safety Culture in Saudi Arabian Hospitals. Quality and Safety in Health Care, 19, 1-5. https://doi.org/10.1136/qshc.2009.033258

[22] El-Jardali, F., Jaafar, M., Dimassi, H., Jamal, D. and Hamdan, R. (2010) The Current State of Patient Safety Culture in Lebanese Hospitals: A Study at Baseline. International Journal for Quality in Health Care, 22, 386-395. https://doi.org/10.1093/intqhc/mzq047

[23] Mikušová, V., Rusnáková, V., Nad’ová, K., Boroňová, J. and Betková, M. (2012) Patient Safety Assessment in Slovak Hospitals. International Journal of Collaborative Research on Internal Medicine and Public Health, 4, No. 6.

[24] Kim, J., An, K., Kim, M. and Yoon, S. (2007) Nurses' Perception of Error Reporting and Patient Safety Culture in Korea. Western Journal of Nursing Research, 29, 827. https://doi.org/10.1177/0193945906297370

[25] Martowirono, K., Wagner, C. and Bijnen, A.B. (2013) Surgical Residents' Perceptions of Patient Safety Climate in Dutch Teaching Hospitals. Journal of Evaluation in Clinical Practice, 20, 121-128. https://doi.org/10.1111/jep.12096

[26] de Wet, C., Johnson, P., Mash, R., McConnachie, A. and Bowie, P. (2010) Measuring Perceptions of Safety Climate in Primary Care: A Cross-Sectional Study. Journal of Evaluation in Clinical Practice, 18, 135-142. https://doi.org/10.1111/j.1365-2753.2010.01537.x

[27] Singer, S., Falwell, A., Gaba, D. and Baker, L. (2008) Patient Safety Climate in US Hospitals: Variation by Management Level. Medical Care, 46, 1149-1156. https://doi.org/10.1097/MLR.0b013e31817925c1

[28] Gallego, H., Westbrook, M., Dunn, A and Braithwhite, J. (2012) Investigating Patient Safety Culture across a Health System: Multilevel Modelling of Differences Associated with Service Types and Staff Demographics. International Journal for Quality in Health Care, 24, 311-320. https://doi.org/10.1093/intqhc/mzs028

[29] Feng, X., Acord, L., Cheng, Y., Zeng, J. and Song, J. (2011) The Relationship between Management Safety Commitment and Patient Safety Culture. International Nursing Review, 58, 249-254. https://doi.org/10.1111/j.1466-7657.2011.00891.x

[30] Pronovost, P., Weast, B., Rosenstein, B., Sexton, J., Holzmueller, C., Paine, L., et al. (2005) Implementing and Validating a Comprehensive Unit-Based Safety Program. Journal of Patient Safety, 1, 33-40. https://doi.org/10.1097/01209203-200503000-00008

[31] Naveh, E., Katz-Navon, T. and Stern, Z. (2006) Readiness to Report Medical Treatment Errors. The Effect of Safety Procedures, Safety Information, and Priority of Safety. Medical Care, 44, 117-123. https://doi.org/10.1097/01.mlr.0000197035.12311.88

[32] Vogus, T. and Sutcliffe, K. (2007) The Impact of Safety Organizing, Trusted Leadership, and Care Pathways on Reported Medication Errors in Hospital Nursing Units. Medical Care, 45, 997-1002. https://doi.org/10.1097/MLR.0b013e318053674f

[33] Pronovost, P., Berenholtz, S. and Goeschel, C. (2008) Improving Patient Safety in Intensive Care Units in Michigan. The Journal of Critical Care, 23, 207-221. https://doi.org/10.1016/j.jcrc.2007.09.002

[34] Mardon, R., Khanna, K., Sorra, J., Dyer, N. and Famolaro, T. (2010) Exploring Relationships between Hospital Patient Safety Culture and Adverse Events. Journal of Patient Safety, 6, 226-232. https://doi.org/10.1097/PTS.0b013e3181fd1a00 
[35] Thorp, J., Baqai, W., Witters, D., Harter, J., Agrawal, S., Kanitkar, K., et al. (2012) Workplace Engagement and Workers' Compensation Claims as Predictors for $\mathrm{Pa}$ tient Safety Culture. Journal of Patient Safety, 8, 194-201. https://doi.org/10.1097/PTS.0b013e3182699942

[36] Reason, J. (2013) Individual and System Models for Malpractice-Creating the Right Balance in Health Care Practice. Chapter 10. In: Ödegård, S., Ed., Patient Safety. Theory and Practice, Liber, Stockholm, 148-169 (In Swedish). [Individ- och systemmodeller för felbehandlingar- att skapa rätt balans i hälso- och sjukvården. In: Ödegård, S., Ed., Patientsäkerhet. Teoriochpraktik, Liber, Stockholm].

[37] Pronovost, P., Sexton, B., Pham, J.C., Goeschel, C., Winters, B and Miller, M. (2009) Measurement of Quality and Assurance of Safety in the Critically Ill. Clinics in Chest Medicine, 30, 169-179. https://doi.org/10.1016/j.ccm.2008.09.004

[38] World Health Organization (2008) World Alliance for Patient Safety Progress Report 2006-2007.

[39] Nieva, V. and Sorra, J. (2003) Safety Culture Assessment: A Tool for Improving Patient Safety in Healthcare Organizations. Quality and Safety in Health Care, 12, ii17-ii23. https://doi.org/10.1136/qhc.12.suppl_2.ii17

[40] Sorra, J. and Nieva, V. (2004) Hospital Survey on Patient Safety Culture. Prepared by Westat under Contract No. 290-96-0004. Agency for Healthcare Research and Quality, Rockville, MD.

[41] The National Board of Health and Welfare (2009) To Measure Patient Safety Culture: Handbook for Patient Safety Work. The National Board of Health and Welfare, Stockholm. Socialstyrelsen (2009). Att mäta patientsäkerhetskulturen. Handbok för patientsäkerhetsarbete. Socialstyrelsen. (In Swedish)

[42] Hedskjöld, M., Pukk-Härenstam, K., Berg, E., Lindh, M., Soop, M., Övretveit, J., et al. (2013) Psychometric Properties of the Hospital Survey on Patient Safety Culture, HSOPSC, Applied on a Large Swedish Health Care Sample. BMC Health Services Research, 13, 332. https://doi.org/10.1186/1472-6963-13-332

[43] Nordin, A., Wilde-Larsson, B., Nordström, G. and Theander, K. (2013) Swedish Hospital Survey on Patient Safety Culture- Psychometric Properties and Health Care Staff's Perception. The Open Nursing Journal, 3, 28-40.

[44] Montgomery, D.C. (2013) Design and Analysis of Experiments. 7th Edition, John Wiley and Sons, Singapore.

[45] NNF (2003) Ethical Guidelines for Nursing Research in the Nordic Countries. Northern Nurses' Federation.

[46] Dixon-Woods, M., Bosk, C., Aveling, E.L., Goeschel, C. and Pronovost, P. (2011) Explaining Michigan: Developing an Ex Post Theory of a Quality Improvement Program. Milbank Quarterly, 89, 167-205. https://doi.org/10.1111/j.1468-0009.2011.00625.x

[47] Amalberti, R. (2013) Quality and Patient Safety at Organizational Changes and Economic Austerity. In: Ödegård, S., Ed., Patient Safety. Theory and Practice, Liber, Stockholm, 195-214. [Kvalitet och patientsäkerhet vid organisatoriska förändringar och ekonomiska åtstramningar. In: Ödegård, S., Ed., Patientsäkerhet. Teoriochpraktik.]

[48] Blake, S.C., Kohler, S., Rask, K., Davis, A. and Naylor, D.V. (2006) Facilitators and Barriers to 10 National Quality Forum Safe Practices. American Journal of Medical Quality, 21, 323-334. https://doi.org/10.1177/1062860606291781

[49] Johnson, K. and Maultsby, C. (2007) A Plan for Achieving Significant Improvement in Patient Safety. Journal of Nursing Care Quality, 22, 164-171. 
https://doi.org/10.1097/01.NCQ.0000263107.92848.4b

[50] Gunnarsdottir, S., Clarke, S.P., Rafferty, A.M. and Nutbeam, D. (2009) Front-Line Management, Staffing and Nurse-Doctor Relationships as Predictors of Nurse and Patient Outcomes. A Survey of Icelandic Hospital Nurses. International Journal of Nursing Studies, 46, 920-927. https://doi.org/10.1016/j.ijnurstu.2006.11.007

[51] Jackson, D., Hutchinson, M., Peters, K., Luck, L. and Saltman, D. (2013) Understanding Avoidant Leadership in Health Care: Findings from a Secondary Analysis of Two Qualitative Studies. Journal of Nursing Management, 21, 572-580. https://doi.org/10.1111/j.1365-2834.2012.01395.x

[52] Aiken, L., Sloane, D., Bruyneel, L., et al. (2014) Nurse Staffing and Education and Hospital Mortality in Nine European Countries: A Retrospective Observational Study. The Lancet, 383, 1824-1830. https://doi.org/10.1016/S0140-6736(13)62631-8

[53] SOU 2013:2. Patients' Act. Proposed from the Patients' Power investigation. Swedish Government 2013. Stockholm. (In Swedish). Patientlagen. Delbetänkande av Patientmaktsutredningen. Statens Offentliga Utredningar.

[54] Weaver, S., Lubomski, L., Wilson, R., Pfoh, E., Martinez, K. and Dy, S. (2013) Promoting a Culture of Safety as a Patient Safety Strategy. A Systematic Review. Annals of Internal Medicine, 158, 369-374. https://doi.org/10.7326/0003-4819-158-5-201303051-00002

[55] Westrum, R. (2004) A Typology of Organisational Cultures. Quality and Safety in Health Care, 13, ii22-ii27. https://doi.org/10.1136/qshc.2003.009522

[56] Wong, C. and Cummings, G. (2007) The Relationship between Nursing Leadership and Patient Outcomes: A Systematic Review. Journal of Nursing Management, 15, 508-521. https://doi.org/10.1111/j.1365-2834.2007.00723.x

[57] Davis, R., Briggs, M., Arora, S., Moss, R. and Schwappach, D. (2014) Predictors of Health Care Professionals' Attitudes towards Involvement in Safety-Relevant Behaviours. Journal of Evaluation in Clinical Practice, 20, 12-19. https://doi.org/10.1111/jep.12073

[58] Hughes, C. and Lapane, K. (2006) Nurses' and Nursing Assistants' Perceptions of Patient Safety Culture in Nursing Homes. International Journal for Quality in Health Care, 18, 281-286. https://doi.org/10.1093/intqhc/mzl020

[59] Bonner, A., MacCulloch, P., Gardner, T. and Chase, C. (2007) A Student-Led Demonstration Project on Fall Prevention in a Long-Term Care Facility. Geriatric Nursing, 28, 312-318. https://doi.org/10.1016/j.gerinurse.2007.04.014

[60] From, I., Nordström, G., Wilde-Larsson, B. and Johansson, I. (2013) Caregivers in Older Peoples' Care: Perception of Quality of Care, Working Conditions, Competence and Personal Health. Scandinavian Journal of Caring Sciences, 27, 704-714. https://doi.org/10.1111/j.1471-6712.2012.01083.x

[61] Frankel, A., Graydon-Baker, E., Neppl, C., Simmonds, T., Gustafson, M. and Gandhi, T. (2003) Patient Safety Leadership Walkrounds. The Joint Commission Journal on Quality and Patient Safety, 29, 16-26. https://doi.org/10.1016/S1549-3741(03)29003-1

[62] Öhrn, A., Rutberg, H. and Nilsen, P. (2011) Patient Safety Dialogue: Evaluation of an Intervention Aimed at Achieving an Improved Patient Safety Culture. Journal of Patient Safety, 7, 185-192. https://doi.org/10.1097/PTS.0b013e318230e702

[63] Quick, J. (2011) Modern Perioperative Teamwork: An Opportunity for Interprofessional Learning. Journal of Perioperative Practice, 21, 387-390. https://doi.org/10.1177/175045891102101104

[64] West, P., Sculli, G., Fore, A., Okam, N., Dunlap, C., Neily, J., et al. (2012) Improving 
Patient Safety and Optimizing Nursing Teamwork Using Crew Management Techniques. The Journal of Nursing Administration, 42, 15-20. https://doi.org/10.1097/NNA.0b013e31823c17c7

[65] Reeves, S., Perrier, L., Goldman, J., Freeth, D. and Zwarenstein, M. (2013) Interprofessional Education: Effects on Professional Practice and Healthcare Outcomes (Update) (Review). Cochrane Database of Systematic Review, No. 3. https://doi.org/10.1002/14651858.CD002213.pub3

[66] Tvedt, C., Sjetne, I., Helgeland, J. and Bukholm, G. (2012) A Cross-Sectional Study to Identify Organisational Processes Associated with Nurse-Reported Quality and Patient Safety. BMJ Open, 2, e001967.

https://doi.org/10.1136/bmjopen-2012-001967

[67] Field, A. (2009) Discovering Statistics Using SPSS. 3rd Edition, Sage, London.

[68] Swedish Association of Local Authorities and Regions (SALAR) Statistics about Staff Employed in County Councils. (In Swedish). Sveriges Kommuneroch Landsting Personalstatistik.

[69] Baruch, Y. (1999) Response Rate in Academic Studies-A Comparative Analysis. Human Relations, 52, 421-438. https://doi.org/10.1177/001872679905200401

[70] Flanigan, T., MacFarlane E. and Cook, S. (2008) Conducting Survey Research among Physicians and Other Medical Professionals: A Review of Current Literature. Section on Survey Research Methods. American Statistical Association.

[71] Altman, D. (1999) Practical Statistics for Medical Research. Chapman and Hall/CRC, London.

[72] Polit, D. and Beck, C. (2012) Nursing Research. Generating and Assessing Evidence for Nursing Practice. 9th Edition, Wolters Kluwer, Lippincott Williams and Wilkins, London. 